\title{
Volatile and Non-volatile Phytochemicals from Roots and Leaves of Heracleum lasiopetalum and their Radical Scavenging Ability
}

\author{
Esmaeil Javidnia $^{1(\mathbb{D})}$, Mir Babak Bahadori ${ }^{2, *(\mathbb{D})}$, Mahdi Abbas-Mohammadi ${ }^{3(\mathbb{D})}$, Hadi Pourjafar ${ }^{2,4}(\mathbb{C}$ \\ 1 Department of Pharmacognosy, Faculty of Pharmacy, Urmia University of Medical Sciences, Urmia, Iran; \\ smko.javid@gmail.com (E.J.); \\ 2 Medicinal Plants Research Center, Maragheh University of Medical Sciences, Maragheh, Iran; Fax number: +98 (041) \\ 37256919; Tel.: +98 (041) 37276363; mb.bahadori@gmail.com (M.B.B.); \\ 3 Department of Phytochemistry, Medicinal Plants and Drugs Research Institute, Shahid Beheshti University, Tehran, Iran; \\ mehdiamohamadi@ymail.com (M.A.M.); \\ 4 Alborz University of Medical Sciences, Dietary supplements and Probiotic Research Center, Karaj, Iran; \\ pourjafarhadi59@gmail.com (H.P.); \\ * Correspondence: mb.bahadori@gmail.com;
}

Scopus Author ID 57217797462

Received: 17.10.2020; Revised: 9.11.2020; Accepted: 12.11.2020; Published: 14.11.2020

\begin{abstract}
Heracleum lasiopetalum belongs to the Apiaceae family and is native to Iran. The fruits and seeds of the herb are used as spices and food additives. The genus has significant pharmacological activities. In order to study the phytochemicals of $H$. lasiopetalum, aerial parts of the plant were conducted to a separation process. Different chromatographic techniques were employed for the purification of its natural products. The chemical structure of the isolated metabolites was determined using spectroscopic methods such as NMR and IR as well as elemental analysis. Moreover, the essential oil composition of roots and aerial parts of the herb were characterized using GC-MS analysis. The purified compounds were elucidated as beta-sitosterol (plant steroid) and suberosin (coumarin). Identification of essential oil composition showed that 17 and 12 volatile compounds were present in the aerial parts and roots of the herb, respectively. Germacrene D, falcarinol, farnesol, and octanal were found as the major components. Findings showed that $H$. lasiopetalum contains important natural products such as steroids, coumarins, monoterpenoids, and sesquiterpenoids. According to its bioactive products, this herb could be considered for more applications in the cosmetics and pharmaceutical industries.
\end{abstract}

Keywords: Heracleum; hogweed; coumarin; steroids; essential oil.

(C) 2020 by the authors. This article is an open-access article distributed under the terms and conditions of the Creative Commons Attribution (CC BY) license (https://creativecommons.org/licenses/by/4.0/).

\section{Introduction}

The genus Heracleum (Apiaceae) comprises more than 120 species in the world [1,2]. Different species of this genus are distributed all around the world, especially in the Northern Hemisphere. Ten species of Heracleum members are representative in Iran, and three of them (H. rechingeri, $H$. gorganicum, $H$. anisactis) are endemic to the country [3].

Different parts of Heracleum members have a lot of uses in folk medicine. They are used for epilepsy, respiratory infections, skin disease, infected wound, gastric ulcers, diarrhea, and dyspepsia [4-6]. Some parts of Heracleum species such as seeds and leaves are used as a vegetable, flavoring agent, additive, and spice in many areas of the world [7, 8]. Modern scientific studies on Heracleum species showed a wide range of biological and https://biointerfaceresearch.com/ 
pharmacological activities. Essential oils of these plants showed anticonvulsant, analgesic, anti-inflammatory, and antifungal effects [9, 10]. Furthermore, significant pharmacological effects such as antioxidant, antibacterial, antiviral, immunostimulant, insecticidal, cytotoxic, gastroprotective, antifolliculogenesis, infertility, and hepatoprotective activity have been reported for extracts of this genus [11-16]. In total, more than 100 natural compounds have been isolated from various Heracleum species [1]. Aliphatic esters and monoterpenes are major compounds in the EOs of the genus [17]. The major isolated non-volatile compounds from Heracleum species are coumarins, anthraquinones, stilbene derivatives, and flavonoids $[1,18,19]$. Also, the most abundant compounds in this genus are coumarins such as bergapten, sphondin, xanthotoxin, pimpinellin, angelicin, candinoside A-D, imperatorin, heraclenin, 8geranyloxypsoralen, and canditririn C-E [1].

Heracleum lasiopetalum (synonym: Tetrataenium lasiopetalum) is distributed in Turkey, Iraq, and Iran. In Iranian folk medicine, H. lasiopetalum is used as an antiseptic, spice, carminative, digestive, flavoring agent, and food additive. Several studies reported the antioxidant and antibacterial activity of this species. H. lasiopetalum Persian name is Golpar or Kersun, and its local name is Kashma in Kurdish regions, and its Turkish name is Baldirqan [20].

In the present study, H. lasiopetalum was subjected to phytochemical investigation. For this, EOs of the aerial parts and roots of the herb were isolated and characterized. Moreover, its dichloromethane extract was conducted to chromatographic separation process for purification of bioactive metabolites. Finally, isolated EOs, together with purified compounds, were evaluated for their radical scavenging activity.

\section{Materials and Methods}

\subsection{Chemicals.}

Column chromatography and preparative thin-layer chromatography experiments were performed using silica gel purchased from Merck (Germany). Solvents were obtained from DaeJung (South Korea) and Carlo Erba (Italy).

\subsection{Plant material.}

The aerial parts and roots of Heracleum lasiopetalum $(3.5 \mathrm{~kg}$ ) were collected in June 2016 from Kanikhoda Mountains, Piranshahr, West Azerbaijan province, Iran. It was identified taxonomically in the herbarium of faculty of pharmacy (UPSH), Urmia University of Medical Sciences, Urmia, Iran. Also, a voucher specimen (UPSH-347) was deposited for the collected plant sample.

\subsection{Preparation of extracts.}

Dried aerial parts of $H$. lasiopetalum were powdered and extracted by the maceration method. For this, $1000 \mathrm{~g}$ of powdered material was extracted with $n$-hexane, dichloromethane, and methanol sequentially on a magnetic shaker for $72 \mathrm{~h}$ at room temperature. After filtration, the solvents were evaporated under reduced pressure by a rotary vacuum evaporator at $40^{\circ} \mathrm{C}$ to produce crude extracts. 


\subsection{Purification of compounds.}

Dichloromethane extract (76 g) was chromatographed on a silica gel column (silica gel $0.063-0.200 \mathrm{~mm}, 600 \mathrm{~g}$ ) and eluted with $n$-hexane-ethyl acetate (100:0 to 0:100), followed by increasing concentrations of methanol (up to 10\%). The volume of each fraction was $200 \mathrm{~mL}$, and 182 fractions were collected in total. Finally, on the basis of thin-layer chromatography (TLC) analysis, similar fractions were combined, and 20 fractions (F1-20) were obtained. TLC analysis of F6 (2.1 g) and F17 (0.6 g) showed clear spots under UV light and were selected for preparative thin-layer chromatography (PTLC) analysis. F6 and F17 were individually loaded on handmade PTLC sheets $(20 \mathrm{mg}$ on each $20 \times 20 \mathrm{~cm}$ plates, 5 plates were used for each fraction), and observed fluorescent lines under UV light were scraped from the plates. Crushed lines were extracted by methanol and ethyl acetate. This procedure led to the purification of two compounds $1(8 \mathrm{mg})$ and $2(12 \mathrm{mg})$, from F6 and F17, respectively. The yield\% for compound 1 was calculated $0.22 \% \mathrm{w} / \mathrm{w}$ and for compound 2 was $0.09 \% \mathrm{w} / \mathrm{w}$ in dichloromethane extract.

\subsection{NMR experiments.}

NMR experiments were carried out on Bruker Avance $400 \mathrm{MHz}$ spectrometers (Bruker, Rheinstatten, Germany), operating at $400 \mathrm{MHz}$ for ${ }^{1} \mathrm{H}$ and $100 \mathrm{MHz}$ for ${ }^{13} \mathrm{C}$ with TMS as inner standard. $\mathrm{CDCl}_{3}$ was applied as the deuterated solvent.

\subsection{FT-IR analysis.}

IR spectra were recorded on a Shimadzu FTIR-8400S spectrophotometer (Japan) by $\mathrm{KBr}$ pellets.

\subsection{Melting point.}

Melting points were determined in open glass capillaries by an Electrothermal melting point apparatus.

\subsection{Elemental analysis.}

Elemental analysis of $\mathrm{C}, \mathrm{H}$, and $\mathrm{N}$ atoms was followed out through the Costech elemental analyzer.

\subsection{Isolation of essential oils.}

Air-dried aerial parts $(100 \mathrm{~g})$ and roots $(50 \mathrm{~g})$ of the plant were crushed and hydrodistilled separately for $3 \mathrm{~h}$ by a Clevenger-type apparatus in one step, conforming to the method of the European Pharmacopoeia. The obtained EOs were dried over anhydrous $\mathrm{Na}_{2} \mathrm{SO}_{4}$ and stored in sealed vials at $4^{\circ} \mathrm{C}$ until analysis [21].

\subsection{GC-MS analysis.}

The EOs were analyzed using a Thermoquest-Finnigan Trace MS instrument equipped with a DB-5 fused silica cap. Column ( $60 \mathrm{~m} \times 0.25 \mathrm{~mm}$ i.d., film thickness $0.25 \mu \mathrm{m})$. The oven temperature was kept at $60^{\circ} \mathrm{C}$ initially, then raised at the rate of $5^{\circ} / \mathrm{min}$ until $250^{\circ}$ and held for $10 \mathrm{~min}$. The transfer line temperature was $250^{\circ} \mathrm{C}$. Helium was used as carrier gas at a flow rate of $1 \mathrm{~mL} / \mathrm{min}$ with a split ratio of $1 / 50$. Injector temperature was set at $250{ }^{\circ} \mathrm{C}$. The quadrupole 
mass spectrometer was used with a scan range between 35-465 amu. Measurements were performed with an ionizing voltage of $70 \mathrm{eV}$ and an ionization current of $150 \mu \mathrm{A}$ [22].

\subsection{Identification of volatile compounds.}

Identification of EOs components was accomplished based on a comparison of their spectra with those of the internal reference mass spectra library (NIST, Wiley, and Adams) or of authentic compounds [23]. Retention indices were calculated and compared with those of literature.

\subsection{Antioxidant activity assessment.}

2,2-Diphenyl-1-picrylhydrazyl (DPPH, molecular formula $\mathrm{C}_{18} \mathrm{H}_{12} \mathrm{~N}_{5} \mathrm{O}_{6}$ ) was utilized for the investigation of the radical scavenging ability of isolated compounds and also EOs (Fluka Chemie AG, Bucks). Rutin was used as the standard drug. Different concentrations of each sample (dissolved in methanol) separately were provided $(7.8-500 \mu \mathrm{g} / \mathrm{mL}$ ). Eight $\mathrm{mg}$ DPPH was dissolved in methanol to provide a concentration of $80 \mu \mathrm{g} / \mathrm{mL}$. One $\mathrm{mL} \mathrm{DPPH}$ solution was mixed with one $\mathrm{mL}$ diluted sample solution and incubated for $30 \mathrm{~min}$ at room temperature for any reaction to occur. After incubation, UV absorbance of each compound was recorded at $517 \mathrm{~nm}$. The experiments were performed in triplicates, and the mean absorption \pm SD was noted for each sample. The same procedure was done by rutin as a positive control [24].

\section{Results and Discussion}

\subsection{Structure elucidation of isolated compounds.}

Chromatographic processes, together with the recrystallization technique, were employed to purify two natural compounds from $H$. lasiopetalum. Compound 1 was obtained as colorless needle crystals. According to the elemental analysis, compound 1 has an empirical formula of $\mathrm{C}_{29} \mathrm{H}_{50} \mathrm{O}$. That was in accordance with plant steroids. The ${ }^{1} \mathrm{HNMR}$ and ${ }^{13} \mathrm{CNMR}$ results for this compound showed the presence of an olefinic bond (120.7 and $139.7 \mathrm{ppm}$ ) and characteristic methyl groups related to steroids (Pentacyclic ursane and oleane triterpenoids generally contain seven methyl groups, but steroids like beta-sitosterol contain six methyl groups of which four have appeared as doublets in ${ }^{1} \mathrm{HNMR}$ spectrum). FT-IR signals revealed the presence of $-\mathrm{OH}$ group in the structure. The comparison of obtained results with those of literature [25], showed the beta-sitosterol structure for compound 1 (Figure 1). Melting point results $\left(138.5-140^{\circ} \mathrm{C}\right)$ were also confirmed by the reported data in the literature [26]. This is the first report on the purification of $\beta$-sitosterol from $H$. lasiopetalum. $\beta$-Sitosterol is a bioactive steroid found in several plants. Different pharmacological properties have been reported for this compound, such as anticancer, anti-inflammatory, anticholinesterase, and hypolipidemic effects [25]. It was isolated previously from $H$. sphondylium, H. pyrenaicum, and $H$. canescens [27].

Compound 2 was obtained as yellowish crystals. Elemental analysis of compound 2 showed the $\mathrm{C}_{15} \mathrm{H}_{16} \mathrm{O}_{3}$ empirical formula for this compound. This formula confirmed the presence of a coumarin backbone. Compound 2 showed aromatic signals and a clear methoxy group in both ${ }^{13} \mathrm{CNMR}$ (54.8 ppm) and ${ }^{1} \mathrm{HNMR}$ (3.9 ppm) spectra. Moreover, the presence of $\mathrm{C}-\mathrm{O}, \mathrm{C}=\mathrm{C}$, and $\mathrm{C}=\mathrm{O}$ functional groups in FT-IR spectrum was observed. A pattern of coumarin 
structure was clear from the spectroscopic data. Finally, compound 2 was elucidated as 7methoxy-6-(3-methylbut-2-enyl)chromen-2-one. This compound is known as suberosin (Figure 2), a simple natural coumarin reported from the Apiaceae family. The recorded melting point $\left(86-89^{\circ} \mathrm{C}\right)$ was also in accordance with previously published data [28]. Suberosin has not been reported from $H$. lasiopetalum and other Heracleum species before. Some biological activities such as insecticidal, antibacterial, anticoagulant, and antifungal properties have been reported for this coumarin compound.
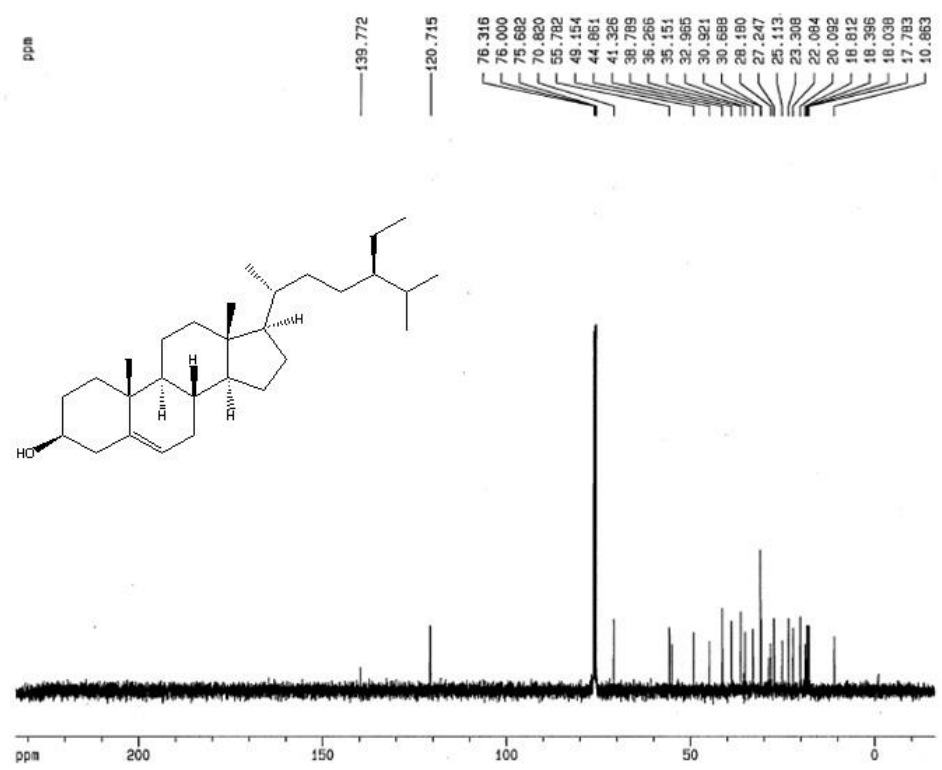

Figure 1. ${ }^{13} \mathrm{CNMR}$ of $\beta$-sitosterol at $100 \mathrm{MHz}$ in $\mathrm{CDCl}_{3}$ and its chemical structure.

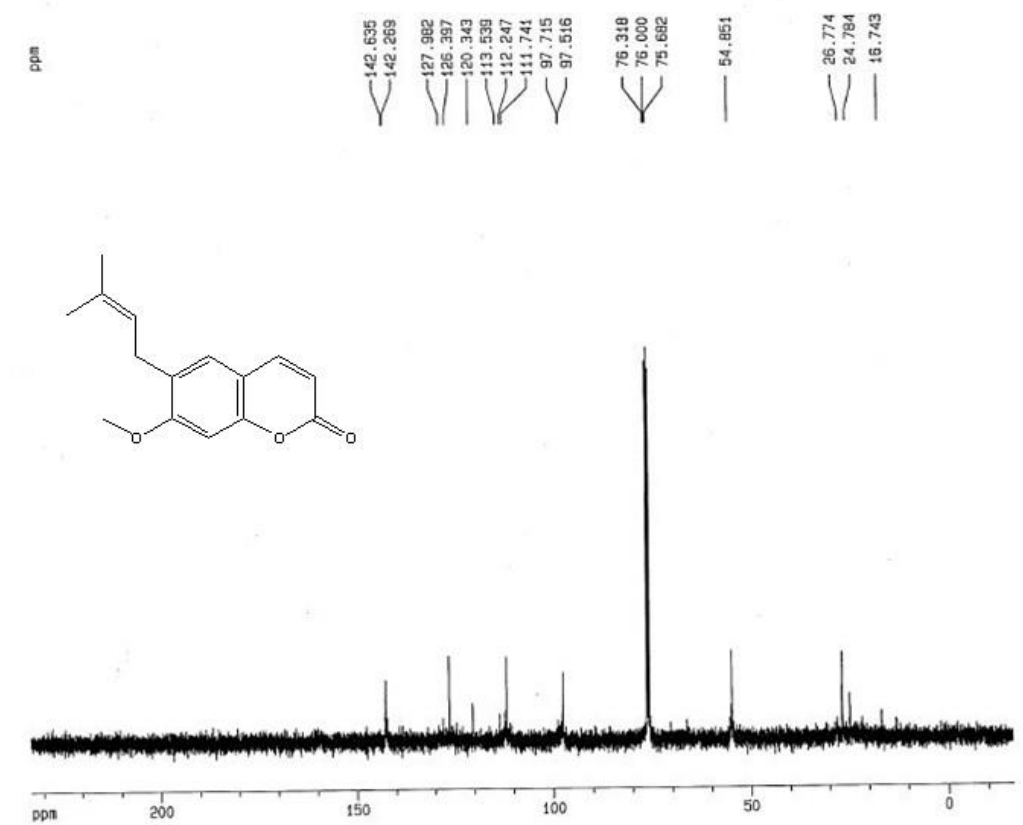

Figure 2. ${ }^{13} \mathrm{CNMR}$ of suberosin at $100 \mathrm{MHz}$ in $\mathrm{CDCl}_{3}$ and its chemical structure.

\subsection{Essential oil composition.}

Constituents of aerial parts and roots EOs of $H$. lasiopetalum, their retention indices, and percentages are depicted in Tables 1 and 2, respectively. The extraction yields of the EOs were $0.4 \%$ and $0.3 \% \mathrm{v} / \mathrm{w}$ for the aerial parts and roots, respectively. The EOs were subjected 
to GC-MS analysis in order to determine their chemical composition. Due to the analysis of the aerial parts EO, 17 components were identified, making up $88.43 \%$ of the total composition. This EO was mainly represented by germacrene D (30.2\%) and farnesol (20.5\%). Generally, Heracleum species contain alkyl esters as main components of their EOs [1]. There is just one study that reported germacrene D (a hydrocarbon sesquiterpenoid) as a predominant compound in $H$. candicans [29], which has antimicrobial and insecticidal properties. Moreover, there is no study reporting farnesol as a major compound in the EOs of the genus Heracleum. Farnesol is acyclic sesquiterpene alcohol and is used in cosmeceutical products due to its flavor and antioxidant effects. The literature review showed that EO of aerial parts of $H$. lasiopetalum ( $T$. lasiopetalum) from Lorestan province contains germacrene D, 2-ethyl hexyl acetate, $\alpha$ zingiberene, and $\beta$-bisabolene as the most abundant volatiles [30]. In that study, similar to the present work, germacrene $\mathrm{D}$ is the dominant compound in aerial parts EO.
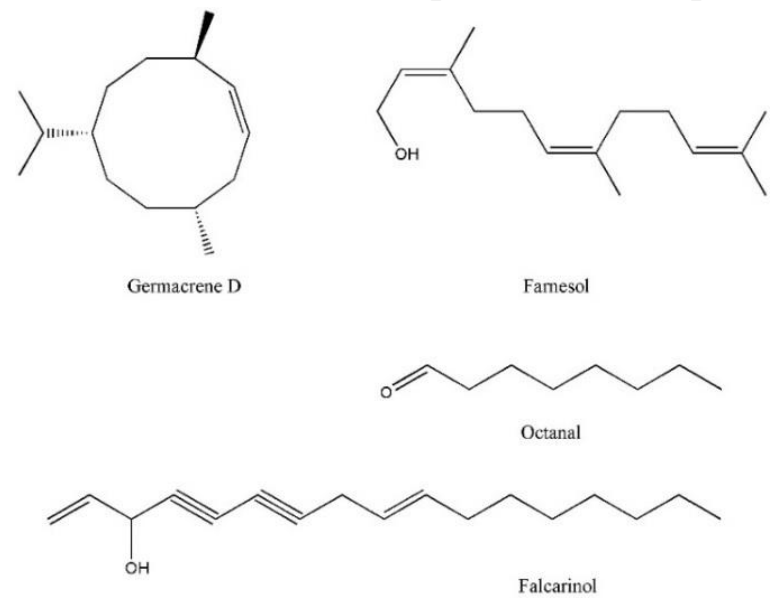

Figure 3. Major volatile components identified in H. lasiopetalum.

Table 1. Chemical composition of H. lasiopetalum aerial parts essential oil.

\begin{tabular}{|c|c|c|c|c|c|c|}
\hline No. & Compound & Class & R.T. (Min) & RI-C & RI-L & Percentage (\%) \\
\hline 1 & 1-Octanol & OT & 7.72 & 1043 & 1046 & 0.2 \\
\hline 2 & $n$-Octyl acetate & ES & 16.30 & 1190 & 1196 & 1.12 \\
\hline 3 & Citronellol acetate & $\mathrm{MO}$ & 21.07 & 1321 & 1335 & 0.18 \\
\hline 4 & Caryophyllene & SH & 24.95 & 1389 & 1394 & 0.21 \\
\hline 5 & n-Octyl 2-methyl butyrate & ES & 26.4 & 1400 & 1413 & 2.02 \\
\hline 6 & Germacrene D & $\mathrm{SH}$ & 28.15 & 1453 & 1459 & 30.2 \\
\hline 7 & Bicyclogermacrene & SH & 28.83 & 1465 & 1470 & 3.56 \\
\hline 8 & Neryl isobutanoate & ES & 28.97 & 1477 & 1475 & 1.23 \\
\hline 9 & $\delta$-Cadinene & $\mathrm{SH}$ & 29.72 & 1489 & 1486 & 0.53 \\
\hline 10 & Neryl isovalerate & ES & 32.18 & 1540 & 1535 & 5.18 \\
\hline 11 & Spathulenol & $\mathrm{SO}$ & 32.94 & 1546 & 1554 & 2.68 \\
\hline 12 & Viridiflorol & SO & 33.24 & 1559 & 1560 & 0.15 \\
\hline 13 & Geranyl isovalerate & $\mathrm{MO}$ & 33.46 & 1566 & 1582 & 6.55 \\
\hline 14 & $\alpha$-Cadinol & $\mathrm{SO}$ & 34.93 & 1622 & 1624 & 2.56 \\
\hline 15 & Farnesol & SO & 36.68 & 1639 & 1665 & 20.57 \\
\hline 16 & Neophytadiene & $\mathrm{D}$ & 42.33 & 1795 & 1830 & 6.96 \\
\hline \multirow[t]{8}{*}{17} & Phytol & $\mathrm{D}$ & 45.37 & 2085 & 2103 & 4.7 \\
\hline & Monoterpenoids (MO) & & & & & 6.73 \\
\hline & Sesquiterpenoid hydrocarbons (SH) & & & & & 34.32 \\
\hline & Oxygenated sesquiterpenoids (SO) & & & & & 25.96 \\
\hline & Diterpenoids (D) & & & & & 11.67 \\
\hline & Esters (ES) & & & & & 9.55 \\
\hline & Other classes $(\mathrm{OT})$ & & & & & 0.2 \\
\hline & Total & & & & & 88.43 \\
\hline
\end{tabular}

RT: Retention time. RI-C: Calculated retention index. RI-L: Retention index from literature. 
For the EO extracted from the roots, 12 volatile components were identified, representing $93.46 \%$ of the total composition (Table 2). The major component of roots EO was falcarinol, with $55.89 \%$ of the EO composition. Falcarinol is fatty alcohol known as a biopesticide. So, falcarinol rich EOs could be utilized as a natural pesticide. This is the first report of falcarinol as a major volatile compound in Heracleum members. The most abundant volatiles in aerial parts and roots of $H$. lasiopetalum could be seen in Figure 3.

Table 2. Chemical composition of H. lasiopetalum roots essential oil.

\begin{tabular}{l|l|l|l|l|l|l} 
No. & Compound & Class & R.T. $($ Min) & RI-C & RI-L & Percentage (\%) \\
\hline $\mathbf{1}$ & Octanal & OT & 7.72 & 973 & 968 & 19.6 \\
\hline $\mathbf{2}$ & Nonanal & OT & 11.51 & 1076 & 1085 & 1.01 \\
\hline $\mathbf{3}$ & Octyl butanoate & ES & 20.13 & 1357 & 1366 & 1.05 \\
\hline $\mathbf{4}$ & n-Octyl 2-methylbutanoate & ES & 21.05 & 1400 & 1413 & 1.33 \\
\hline $\mathbf{5}$ & $\gamma$-Decalactone & OT & 27.35 & 1437 & 1439 & 1.46 \\
\hline $\mathbf{6}$ & (2E)-Tridecenal & OT & 31.55 & 1518 & 1537 & 3.87 \\
\hline $\mathbf{7}$ & Spathulenol & SO & 32.91 & 1545 & 1548 & 2.75 \\
\hline $\mathbf{8}$ & Hexahydrofarnesyl acetone & OT & 40.12 & 1800 & 1801 & 1.04 \\
\hline $\mathbf{9}$ & Methyl palmitate & ES & 44.64 & 1880 & 1894 & 2.51 \\
\hline $\mathbf{1 0}$ & Falcarinol & PA & 48.44 & 1994 & 2038 & 55.89 \\
\hline $\mathbf{1 1}$ & Tricosane & AL & 56.48 & 2295 & 2300 & 1.1 \\
\hline $\mathbf{1 2}$ & Tetracosane & AL & 59.33 & 2394 & 2400 & 1.85 \\
\hline
\end{tabular}

\begin{tabular}{l|l|l|l|l|l|l}
\hline & Oxygenated sesquiterpenoids (SO) & & & & & 2.75 \\
\hline & Esters (ES) & & & & & 4.89 \\
\hline & Polyacetylenes (PA) & & & & & 55.89 \\
\hline & Other classes (OT) & & & & & 26.98 \\
\hline & Alkanes (AL) & & & & & 2.95 \\
\hline & Total & & & & & \\
\hline
\end{tabular}

RT: Retention time. RT-C: Calculated retention index. RT-L: Retention index from literature.

\subsection{Antioxidant activity.}

In living systems, antioxidants play a significant role in the prevention of many chronic diseases like cancer, coronary heart disease, diabetes mellitus, Alzheimer's disease, Parkinson's diseases, hypertension, and other degenerative diseases [31]. In this study, the antiradical activity of the isolated compounds, together with EOs was evaluated. In this direction, DPPH radical scavenging activity of studied samples was demonstrated (Table 3). The EO of roots showed the highest radical scavenging effect $(58.6 \mu \mathrm{g} / \mathrm{mL})$, followed by EO of aerial parts $(77.9 \mu \mathrm{g} / \mathrm{mL})$. H. sphondylium subsp. ternatum (mainly composed of octyl acetate, octyl butanoate, and octyl hexanoate) exhibited week radical scavenging activity against DPPH and ABTS radicals [32]. In another study, EOs of $H$. transcaucasicum and $H$. anisactis roots, which were rich in myristicin, indicated antioxidant activity with $\mathrm{IC}_{50}$ values of 54 and $77 \mu \mathrm{g} / \mathrm{mL}$, respectively [33]. Previous work on DPPH radical scavenging activity of $H$. lasiopetalum showed $\mathrm{IC}_{50}$ value of $170 \mu \mathrm{g} / \mathrm{mL}$ for the hydroalcoholic extract of its flowers [34].

Table 3. Radical scavenging activity of $H$. lasiopetalum.

\begin{tabular}{l|l} 
Compound & $\mathbf{I C}_{\mathbf{5 0}}(\boldsymbol{\mu} \mathbf{g} / \mathbf{m L})$ \\
\hline$\beta$-Sitosterol & 182.212 .4 \\
\hline Suberosin & $97.7 \pm 9.2$ \\
\hline Root EO & $58.6 \pm 4.9$ \\
\hline Aerial parts EO & $77.9 \pm 6.8$ \\
\hline Rutin & $22.1 \pm 1.6$
\end{tabular}




\section{Conclusions}

The chemical composition of essential oils and also dichloromethane extract of Heracleum lasiopetalum from the Kanikhoda Mountains was investigated for the first time. Falcarinol, germacrene, farnesol, octanal, beta-sitosterol, and suberosin were identified as the major components of this herb. Moreover, radical scavenging activity of the EOs and pure compounds were evaluated, and strong antioxidant activity was observed. Findings showed that $H$. lasiopetalum has promising potential to be considered for possible uses as pharmaceuticals and cosmeceuticals based on its bioactive components.

\section{Funding}

This research received no external funding.

\section{Acknowledgments}

The financial support of Urmia University of Medical Sciences is acknowledged.

\section{Conflicts of Interest}

The authors declare no conflict of interest.

\section{References}

1. Bahadori, M.B.; Dinparast, L.; Zengin, G. The genus Heracleum: a comprehensive review on its phytochemistry, pharmacology, and ethnobotanical values as a useful herb. Compr Rev Food Sci Food Saf 2016, 15, 1018-1039.

2. Vladimirov, V.; Petrova, A.; Barzov, Z.; Gudžinskas, Z. The alien species of Heracleum (Apiaceae) in the Bulgarian flora revisited. Phytol. Balcan 2019, 25, 395-405.

3. Hazrati, S.; Mollaei, S.; Rabbi Angourani, H.; Hosseini, S.J.; Sedaghat, M.; Nicola, S. How do essential oil composition and phenolic acid profile of Heracleum persicum fluctuate at different phenological stages? Food Sci Nutr 2020, https://doi.org/10.1002/fsn3.1916.

4. Hosseinzadeh, Z.; Ramazani, A.; Razzaghi-Asl, N. Plants of the genus Heracleum as a source of coumarin and furanocoumarin. J Chem Rev 2019, 1, 78-98, https://doi.org/10.33945/SAMI/JCR.2019.1.7898.

5. Gurbuz, P. Flavonoid Glycosides from Heracleum pastinaca Fenzl. Turkish Journal of Pharmaceutical Sciences 2019, 16, 191-196, https://doi.org/10.4274/tjps.galenos.2018.53215.

6. Karmanov, A.P.; Kocheva, L.S.; Belyy, V.A. Topological structure and antioxidant properties of macromolecules of lignin of hogweed Heracleum sosnowskyi Manden. Polymer 2020, 202, https://doi.org/10.1016/j.polymer.2020.122756.

7. Zihare, L.; Gusca, J.; Spalvins, K.; Blumberga, D. Priorities determination of using bioresources. Case study of Heracleum sosnowskyi. Environmental and Climate Technologies 2019, 23, 242-256, https://doi.org/10.2478/rtuect-2019-0016.

8. Daemi-Saeidabad, M.; Shojaeiyan, A.; Vivian-Smith, A.; Stenøien, H.K.; Falahati-Anbaran, M. The taxonomic significance of ddRADseq based microsatellite markers in the closely related species of Heracleum (Apiaceae). PLoS One 2020, 15, https://doi.org/10.1371/journal.pone.0232471.

9. Ehsani, A.; Rezaeiyan, A.; Hashemi, M.; Aminzare, M.; Jannat, B.; Afshari, A. Antibacterial activity and sensory properties of Heracleum persicum essential oil, nisin, and Lactobacillus acidophilus against Listeria monocytogenes in cheese. Veterinary world 2019, 12, 90-96, https://doi.org/10.14202/vetworld.2019.90-96.

10. Ušjak, L.; Niketić, M.; Drobac, M.; Petrović, S. Chemosystematic evaluation of leaf and flower essential oils of eight Heracleum taxa from Southeastern Europe. Plant Syst Evol 2020, 306, https://doi.org/10.1007/s00606-020-01645-z.

11. Changxing, L.; Dongfang, D.; Lixue, Z.; Saeed, M.; Alagawany, M.; Farag, M.; Chenling, M.; Jianhua, L. Heracleum persicum: Chemical composition, biological activities and potential uses in poultry nutrition. Worlds Poult Sci J 2019, 75, 207-218, https://doi.org/10.1017/S0043933919000205.

12. Ozek, G.; Yur, S.; Goger, F.; Ozek, T.; Andjelkovic, B.; Godjevac, D.; Sofrenic, I.; Aneva, I.; Todorova, M.; Trendafilova, A. Furanocoumarin Content, Antioxidant Activity, and Inhibitory Potential of Heracleum verticillatum, Heracleum sibiricum, Heracleum angustisectum, and Heracleum ternatum Extracts against 
Enzymes Involved in Alzheimer's Disease and Type II Diabetes. Chem Biodivers 2019, 16, https://doi.org/10.1002/cbdv.201800672.

13. Uysal, A.; Ozer, O. Y.; Zengin, G.; Stefanucci, A.; Mollica, A.; Picot-Allain, C.M.N.; Mahomoodally, M. F. Multifunctional approaches to provide potential pharmacophores for the pharmacy shelf: Heracleum sphondylium L. subsp. ternatum (Velen.) Brummitt. Comput Biol Chem 2019, 78, 64-73, https://doi.org/10.1016/j.compbiolchem.2018.11.018.

14. Dehghan, H.; Rezaee, P.; Aliahmadi, A. Bioassay screening of 12 Iranian plants and detection of antibacterial compounds from Heracleum persicum using a TLC bioautography method. J Liq Chromatogr Rel Technol 2020, 43, 1-7, https://doi.org/10.1080/10826076.2020.1725557.

15. Majidi, Z.; Mohajjel-Nayebi, A.; Vatankhah, A.M.; Asnaashari, S.; Zakeri-Milani, P. Effects of Heracleum persicum Hydroalcoholic Extract on Insulin, Serum Anti-Oxidant Enzymes, Glucose, and Lipid Profiles in Alloxan-Induced Diabetic Rats. Iran J Med Sci 2020, 45, https://doi.org/10.30476/ijms.2019.45805.

16. Amani, Z.; Gandomi, H.; Akhondzadeh Basti, A.; Derakhshandeh, A.; Noori, N. Cytotoxicity, genotoxicity, and mutagenicity potential of ethanolic extract of Heracleum persicum Desf. ex Fischer. J Food Saf 2019, 39, https://doi.org/10.1111/jfs.12640.

17. Matoušková, M.; Jurová, J.; Grul’ová, D.; Wajs-Bonikowska, A.; Renčo, M.; Sedlák, V.; Poráčová, J.; Gogal'ová, Z.; Kalemba, D. Phytotoxic effect of invasive Heracleum mantegazzianum essential oil on dicot and monocot species. Molecules 2019, 24, https://doi.org/10.3390/molecules24030425.

18. Zhang, C.; Deng, S.; Chen, L.; Yang, M.; Wang, B.; Zhang, X.; Gao, Y.; Zhang, H. A new coumarin isolated from the roots of Heracleum dissectum Ledeb. Nat Prod Res 2020, 1-6, https://doi.org/10.1080/14786419.2020.1810033.

19. Zhang, C.; Gao, Y.; Peng, Y.; Zhang, X.; Zhang, H. A new coumarin from the Roots of Heracleum dissectum. Nat Prod Commun 2019, 14, https://doi.org/10.1177/1934578X1901400129.

20. Yazdan-Bakhsh, M.; Nasr-Esfahani, M.; Esmaeilzadeh-Kenari, R.; Fazel-Najafabadi, M. Evaluation of antioxidant properties of Heracleum Lasiopetalum extract in multilayer nanoemulsion with biopolymer coating to control oxidative stability of sunflower oil. J Food Meas Charact 2020, 1-10, https://doi.org/10.1007/s11694-020-00691-y.

21. Sonboli, A.; Bahadori, M. B.; Dehghan, H.; Aarabi, L.; Savehdroudi, P.; Nekuei, M.; Pournaghi, N.; Mirzania, F. Chemotaxonomic importance of the essential-oil composition in two subspecies of Teucrium stocksianum boiss. From Iran. Chem Biodivers 2013, 10, 687-694, https://doi.org/10.1002/cbdv.201200088.

22. Bahadori, M.B.; Dinparast, L.; Zengin, G.; Sarikurkcu, C.; Bahadori, S.; Asghari, B.; Movahhedin, N. Functional components, antidiabetic, anti-Alzheimer's disease, and antioxidant activities of Salvia syriaca L. Int J Food Prop 2017, 20, 1761-1772, https://doi.org/10.1080/10942912.2016.1218893.

23. Asghari, B.; Zengin, G.; Bahadori, M.B.; Abbas-Mohammadi, M.; Dinparast, L. Amylase, glucosidase, tyrosinase, and cholinesterases inhibitory, antioxidant effects, and GC-MS analysis of wild mint (Mentha longifolia var. calliantha) essential oil: A natural remedy. Eur J Integr Med 2018, 22, 44-49, https://doi.org/10.1016/j.eujim.2018.08.004.

24. Asghari, B.; Mafakheri, S.; Zarrabi, M.; Erdem, S.; Orhan, I.; Bahadori, M.B. Therapeutic target enzymes inhibitory potential, antioxidant activity, and rosmarinic acid content of Echium amoenum. S Afr J Bot 2019, 120, 191-197, https://doi.org/10.1016/j.sajb.2018.05.017.

25. Bahadori, M.B.; Dinparast, L.; Valizadeh, H.; Farimani, M.M.; Ebrahimi, S.N. Bioactive constituents from roots of Salvia syriaca L.: Acetylcholinesterase inhibitory activity and molecular docking studies. S Afr J Bot 2016, 106, 1-4, https://doi.org/10.1016/j.sajb.2015.12.003.

26. Valizadeh, H.; Mahmoodi, K.F.; Alizadeh, Z.; Bahadori, M.B. Isolation and structure elucidation of secondary metabolites from Echinophora platyloba DC from Iran. J Med Plants 2014, 1, 15-21.

27. Ušjak, L.; Sofrenić, I.; Tešević, V.; Drobac, M.; Niketić, M.; Petrović, S. Fatty acids, sterols, and triterpenes of the fruits of 8 Heracleum taxa. Nat Prod Commun 2019, 14, 1-7, https://doi.org/10.1177/1934578X19856788.

28. Murayama, M.; Seto, E.; Okubo, T.; Morita, I.; Dobashi, I.; Maehara, M. Synthetic studies on suberosin and osthol. Chem Pharm Bull 1972, 20, 741-746, https://doi.org/10.1248/cpb.20.741.

29. Chauhan, R.; Nautiyal, M.; Tava, A.; Cecotti, R. Essential oil composition from leaves of Heracleum candicans Wall.: A sustainable method for extraction. J Essent Oil Res 2014, 26, 130-132, https://doi.org/10.1080/10412905.2013.868330.

30. Sonboli, A.; Azizian, D.; Yousefzadi, M.; Kanani, M.; Mehrabian, A. Volatile constituents and antimicrobial activity of the essential oil of Tetrataenium lasiopetalum (Apiaceae) from Iran. Flavour Frag J 2007, 22, 119-122, https://doi.org/10.1002/ffj.1767.

31. Bahadori, M. B.; Zengin, G.; Bahadori, S.; Dinparast, L.; Movahhedin, N. Phenolic composition and functional properties of wild mint (Mentha longifolia var. calliantha (Stapf) Briq.). Int J Food Prop 2018, 21, 183-193, https://doi.org/10.1080/10942912.2018.1440238.

32. Maggi, F.; Quassinti, L.; Bramucci, M.; Lupidi, G.; Petrelli, D.; Vitali, L.A.; Papa, F.; Vittori, S. Composition and biological activities of hogweed [Heracleum sphondylium L. subsp. ternatum (Velen.) Brummitt] essential oil and its main components octyl acetate and octyl butyrate. Nat Prod Res 2014, 28, 1354-1363, https://doi.org/10.1080/14786419.2014.904311. 
33. Torbati, M.; Nazemiyeh, H.; Lotfipour, F.; Nemati, M.; Asnaashari, S.; Fathiazad, F. Chemical composition and in vitro antioxidant and antibacterial activity of Heracleum transcaucasicum and Heracleum anisactis roots essential oil. Bioimpacts 2014, 4, https://doi.org/10.5681/bi.2014.004.

34. Dehshiri, M.M.; Aghamollaei, H.; Zarini, M.; Nabavi, S.M.; Mirzaei, M.; Loizzo, M.R.; Nabavi, S.F. Antioxidant activity of different parts of Tetrataenium lasiopetalum. Pharm Biol 2013, 51, 1081-1085, https://doi.org/10.3109/13880209.2013.775594. 